\title{
Ocular Manifestations in Patients with Philadelphia-Negative Myeloproliferative Neoplasms
}

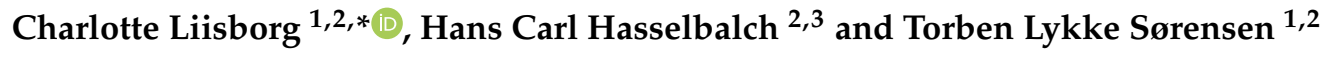 \\ 1 Department of Ophthalmology, Zealand University Hospital, Vestermarksvej 23, 4000 Roskilde, Denmark; \\ tlso@regionsjaelland.dk \\ 2 Faculty of Health and Medical Sciences, University of Copenhagen, Blegdamsvej 3B, 2200 Copenhagen, \\ Denmark; hkhl@regionsjaelland.dk \\ 3 Department of Haematology, Zealand University Hospital, Vestermarksvej 15-17, 4000 Roskilde, Denmark \\ * Correspondence: Liisborg@c.dk; Tel.: +45-4264-6465
}

Received: 29 January 2020; Accepted: 28 February 2020; Published: 2 March 2020

check for updates

\begin{abstract}
The major complications of Philadelphia-negative (Ph-Negative) myeloproliferative neoplasms (MPNs) are thrombosis, haemorrhage and leukemic transformation. As systemic and haematological diseases, MPNs have the potential to affect many tissues and organs. Some complications lead to the diagnosis of MPNs, but other signs and symptoms are often misdiagnosed or neglected as a sign of MPN disease. Therefore, we reviewed the current literature to investigate and delineate the clinical manifestations seen in the eyes of Ph-negative MPN patients. We found that ocular manifestations are common among patients with MPNs. The most frequently described manifestations are due to the consequences of haematological abnormalities causing microvascular disturbances and hyperviscosity. More serious and vision-threatening complications as thrombotic events in the eyes have been repeatedly reported as well. These ocular symptoms may precede more serious extraocular complications. Accordingly, combined ophthalmological and haematological management have the potential to discover these diseases earlier and prevent morbidity and mortality in these patients. Furthermore, routine ophthalmological screening of all newly diagnosed MPN patients may be a preventive approach for early diagnosis and timely treatment of the ocular manifestations.
\end{abstract}

Keywords: ocular manifestations; ocular complications; philadelphia-negative myeloproliferative neoplasms

\section{Introduction}

The Philadelphia-negative (Ph-negative) myeloproliferative neoplasms (MPNs) include essential thrombocytosis (ET), polycythaemia vera (PV) and primary myelofibrosis (PMF), and they are acquired clonal hematopoietic stem-cell disorders. They all share the characteristic that they affect the signal-transduction pathways responsible for haematopoiesis. In addition, the majority of the MPN patients have the JAK2V617F mutation (95-98\% of PV patients and in 50\% to 60\% of ET and PMF patients) [1]. In patients with ET thrombocytosis is prevailing, although a subset of patients may have leukocytosis as well. Patients with PV are characterised by erythrocytosis and-if not present at the time of diagnosis-virtually all patients will develop leukocytosis and thrombocytosis during the course of the disease. The classic PMF is featured by anaemia, variable changes in platelet and leukocyte counts, bone marrow fibrosis, and splenomegaly. The early phase of PMF with thrombocytosis, a normal or only slightly decreased $\mathrm{Hb}$-concentration, and a moderately elevated leukocyte count may mimic ET $[2,3]$.

The Ph-negative MPNs as systemic and haematological diseases have the potential to influence many tissues and organs. The major causes of morbidity and mortality are due to the fact that patients 
are prone to thrombotic and haemorrhagic events and also leukemic transformation [2,3], but other manifestations are seen, including ocular. Ocular signs and symptoms have been described many times in MPN patients, and the complications seen vary and are often secondary to the haematological disturbances pathognomonic for these diseases. These symptoms are often misdiagnosed as other ocular disorders.

To our knowledge, no overview of all the ocular manifestations in these specific patients exists; we, therefore, reviewed the current literature to summarize the ophthalmological complications observed in patients with Ph-negative MPNs. Knowledge of ocular involvement in MPNs is of clinical relevance to these patients and the health personnel in general. The ophthalmologist may play an essential role in patients with MPNs since these patients are often undiagnosed until they develop major thrombotic events. Ocular lesions or symptoms may precede serious extraocular complications related to MPNs. Therefore, the possibility of an underlying haematological disorder should be considered in cases with suspicious or rare ocular findings. Awareness of these symptoms can bring along early recognition and timely initiation of appropriate treatment, which lessens morbidity and mortality in these patients.

\section{Method}

We searched Pubmed for relevant English language literature. We used the search string "myeloproliferative disorders" [MeSH] AND "Eye diseases" [MeSH]. Moreover, we searched for "Myeloproliferative neoplasms" AND "eye disease" and besides, we made searches with the keywords "ocular", "ophthalmic", "eye", "ophthalmological" along with "myeloproliferative neoplasms", "complications", "manifestations". We did this to find the articles not discovered in the first searches. Finally, we reviewed the references from the gathered publications to eliminate the possibility of overlooking publications not found by the search strategy. We found 49 case stories, 7 case series, 12 studies (observational, interventional or register-based) and two reviews on neurological symptoms in MPNs, including ocular symptoms. We also used references where transient ischemic attacks related to MPNs were described.

\section{Ocular Manifestations Prevalence and Pathophysiology}

Studies suggest that the prevalence of ocular complications in ET and PV patients is high, between $7.5-25 \%$ in studies of both treated and untreated patients [4-9]. The ocular structures can be involved directly or indirectly. Direct involvement is seen, but the ocular manifestations in MPNs are primarily due to indirect involvement of the ocular structures. These indirect manifestations arise from haematological abnormalities, neurological involvement or may be due to adverse effects from treatment. The most commonly described eye manifestations in ET and PV are symptoms related to the haematological abnormalities of the MPNs such as thrombocytosis, erythrocytosis and leukocytosis. These changes in blood composition give microvascular circulation disturbances caused by aggregation and spontaneous activation of leukocytes and platelets, and hyperviscosity, primarily caused by the elevated haematocrit due to an expanded red blood cell mass. A result of the haematological disturbances is the more severe ocular and vision-threatening manifestations; thrombotic events in the eyes such as arterial or venous occlusion, where vision loss often is irreversible. The microvascular disturbances can also cause inadequate cerebral perfusion and consequently, possible visual symptoms. These vary from monocular blindness, transient blindness, amaurosis fugax, scotomas, hemianopsia, blurring and hallucinations. These neuro-ophthalmological symptoms manifesting in the eyes are often described as visual symptoms related to atypical transient ischemic attacks (TIAs) or migraine-like ischemic attacks (MIAs). The symptoms disappear when elevated blood elements are normalised by treatment $[4,5,10-15]$.

Finally, other effects or ocular symptoms may occur related to treatment.

It is a different matter with PMF. In the early phase, leukocytosis and thrombocytosis are common and can cause the same symptoms as mentioned above but to a lesser degree [16]. As noted above, the late phase of PMF is characterised by bone marrow failure with anaemia, leukopenia, 
thrombocytopenia and immunosuppression. Therefore, the manifestations seen in these patients are more often related to anaemia associated with ischemic retinopathy, neovascularisation, retinal haemorrhages and cotton wool spots [17]. Direct involvement of the eyes in the form of extramedullary haematopoiesis is also seen in PMF, similar to different leukaemias [18-22].

The important message for the clinicians is not only to treat the ocular lesions or symptoms according to the standard of care but to consider the possibility of an underlying MPN and initiate timely and appropriate treatment since the symptoms often disappear by treatment of the MPNs. The various ocular manifestations in MPNs are described below and shown in Table 1.

Table 1. Ocular manifestations in patients with myeloproliferative neoplasms.

\begin{tabular}{cc}
\hline Site or Cause of Involvement & Ocular Manifestations \\
\hline External eye involvement & EMH \\
\hline Orbit & Pachydermoperiostosis (PDP) \\
\hline Eyelid & EMH \\
\hline Lacrimal gland & \\
\hline Anterior segment diseases & Haemorrhage, thrombosis, conjunctivitis/injection \\
\hline Conjunctiva & Neovascular glaucoma \\
\hline Iris & Angle
\end{tabular}

Posterior segment diseases

\begin{tabular}{cc}
\hline Retina & $\begin{array}{c}\text { Haemorrhages, vascular occlusions, venous dilation and tortuosity, changes } \\
\text { in blood flow, cotton wool spots, Roth spots, AMD, peripheral } \\
\text { neovascularisation, thinner nerve fibre layer, neuronal hypofunction }\end{array}$ \\
\hline Choroid & Changes in blood flow \\
\hline Optic nerve & AION, EMH, papilledema \\
\hline CNS related to eyes & $\begin{array}{r}\text { Blurred vision, transient monocular blindness, amaurosis fugax, } \\
\text { scintillating scotomas, hemianopsia, hallucinations }\end{array}$ \\
\hline Secondary to treatment & Possible AION, retinopathy and irritative conjunctivitis \\
\hline interferon-alpha & Opportunistic infections \\
\hline Ruxolitinib &
\end{tabular}

EMH: extramedullary haematopoiesis, AMD: Age-related macular degeneration, AION: anterior ischemic optic neuropathy. PDP: Pachydermoperiostosis.

\subsection{External Eye Involvement}

Orbit, Eyelid and Lacrimal Gland Involvement

Involvement of the external structures of the eye is described sparsely in the literature. We found two case reports describing PMF patients, with extramedullary hematopoietic tumours (sclerosing extramedullary hematopoietic tumours, SEMHT) in the orbit and lacrimal gland, respectively $[23,24]$. Extramedullary haematopoiesis $(\mathrm{EMH})$ is the production of blood cells outside the bone marrow. In most cases, it is the liver, spleen or lymph nodes that are involved, but any organ can be the site of EMH. EMH occurs in many haematological disorders such as leukaemias, lymphomas and haemolytic anaemias and is often the result of ineffective erythropoiesis or bone marrow dysfunction [24,25].

We also found two cases of pachydermoperiostosis (PDP) associated with PMF [26,27]. PDP is a disease characterised by soft tissue hyperplasia. Patients with the disease have an appearance of tarsitis with thickened tarsal plates and ptosis. 


\subsection{Anterior Segment Diseases}

\subsubsection{Cornea}

We found no literature of involvement of the cornea related to MPNs. The cornea is an avascular structure, which is why it seems plausible that the haematological changes in MPNs do not affect this part of the eye.

\subsubsection{Conjunctiva}

$\mathrm{Na}$ et al. described an unusual case report of simultaneous haemorrhage and infarction of the conjunctiva and intraconal space in an ET patient [28]. The risk of haemorrhage increases with high platelet count $\left(>1500 \times 10^{9} / \mathrm{L}\right)$, which is thought to be associated with loss of von Willebrand factor resulting in acquired von Willebrand factor syndrome [29]. The haemorrhage made sense in this case, because of the high platelet count $\left(1270 \times 10^{9} / \mathrm{L}\right)$, but the authors also found necrotic tissue. Because of the rich blood supply in the conjunctiva, necrosis due to vascular obstruction is uncommon in this structure. Taking into account that the risk of arterial thrombosis is lower with a high platelet count $\left(>1000 \times 10^{9} / \mathrm{L}\right)[30]$ it makes the observed infarction unusual.

Another case describes an undiagnosed PV patient with severely injected conjunctivas and unsuccessful treatment for several months where both antibiotics, steroids and artificial tears were attempted. A scraping and conjunctival biopsy were interpreted as vascular congestion and the blood work led to the diagnoses of PV. The eye symptoms disappeared after the initiation of treatment for PV [31].

Extramedullary haematopoiesis is also reported in the conjunctiva for two PMF patients [32].

\subsubsection{Iris and Angle}

One case of inflammation of the iris, iritis, in an ET patient has been documented [33], and one case of paraneoplastic infiltration of the uveal tract in both eyes resulting in narrow angle-closure glaucoma described [20]. Glaucoma, where the intraocular pressure is high, causing possible damage to the optic nerve, has been reported several times as a cause of underlying MPN disease in all three types of MPNs, and some of the cases where due to neovascular glaucoma secondary to occlusion of the retinal vessels $[19,20,34,35]$.

\subsection{Posterior Segment Diseases}

\subsubsection{Retina and Choroid}

The appearance of the fundus in especially untreated or newly diagnosed MPN patients is venous dilation and tortuosity, haemorrhages, cotton wool spots and occasionally Roth spots. These changes often disappear after treatment [14,16,18,19,28,31,33-43], but most of the literature on the subject consists of case stories. A study by Carraro et al. investigated retinopathy and associated fundus lesions in haematological disorders with anaemia and thrombocytopenia [18]. The study included, among other conditions, patients with myelofibrosis and myelodysplastic syndromes. Only three patients with myelofibrosis were included; two of them had fundus lesions. Of the patients with MDS, six of 16 patients had fundus lesions. The fundus lesions discussed in this study were retinal haemorrhages, exudates, papilledema. The authors observed that the prevalence of retinopathy and fundus lesions increased with the severity of the anaemia or thrombocytopenia.

Disease affecting the retina has been reported. Age-related macular degeneration (AMD), is a disease affecting the retina and is the major cause of blindness in developed countries [44]. A fundus photograph of an ET patient with AMD is shown in Figure 1. A large Danish register-based cohort study, including 7958 patients with MPNs and 77,445 controls, found a higher risk of AMD in these patients. The overall adjusted hazard ratio (HR) was reported as 1.3 (95\% CI 1.1-1.5). The lowest risk was found for patients with ET (adjusted HR 1.2, 95\% CI 1.0-1.6) and the risk increased for patients 
with PV (adjusted HR 1.4, 95\% CI 1.2-1.7) and even further for patients with PMF (adjusted HR 1.7, 95\% CI 0.8-4.0). The authors suggest that the association between MPNs and AMD may be explained partly by inflammatory mechanisms [45]. Because of the hyperviscosity and microvascular disturbances in MPN, we speculate that ischemia may also play a part in the development of AMD. Others have shown that reduced choroidal and retinal blood flow is present in patients with both early and late AMD, and therefore ischemia could be a part of the pathogenesis [45-48]. In accordance, ischemic retinopathy and neovascularisation are documented in PV and PMF patients [49,50], and blood flow in the ophthalmic structures is investigated in a few studies; one by Dapling et al. looked at 15 patients with ET and PV and all but one had normal fluorescein angiograms, suggesting that ongoing microvascular damage is not a significant feature of thrombocytosis due to myeloproliferative disease. Of these 15 patients, four did not receive antiplatelet treatment, and one patient received only cytoreductive treatment in the form of Hydroxyurea. Ten patients received aspirin and five of them in combination with cytoreductive drugs. The platelet counts of the patients were in the range of $393-746 \times 10^{9} / \mathrm{L}$. The patients were asymptomatic, and most of them in treatment, and it was concluded that there was no intrinsic retinal vasculopathy in patients with elevated platelet counts secondary to myeloproliferative disease [51].

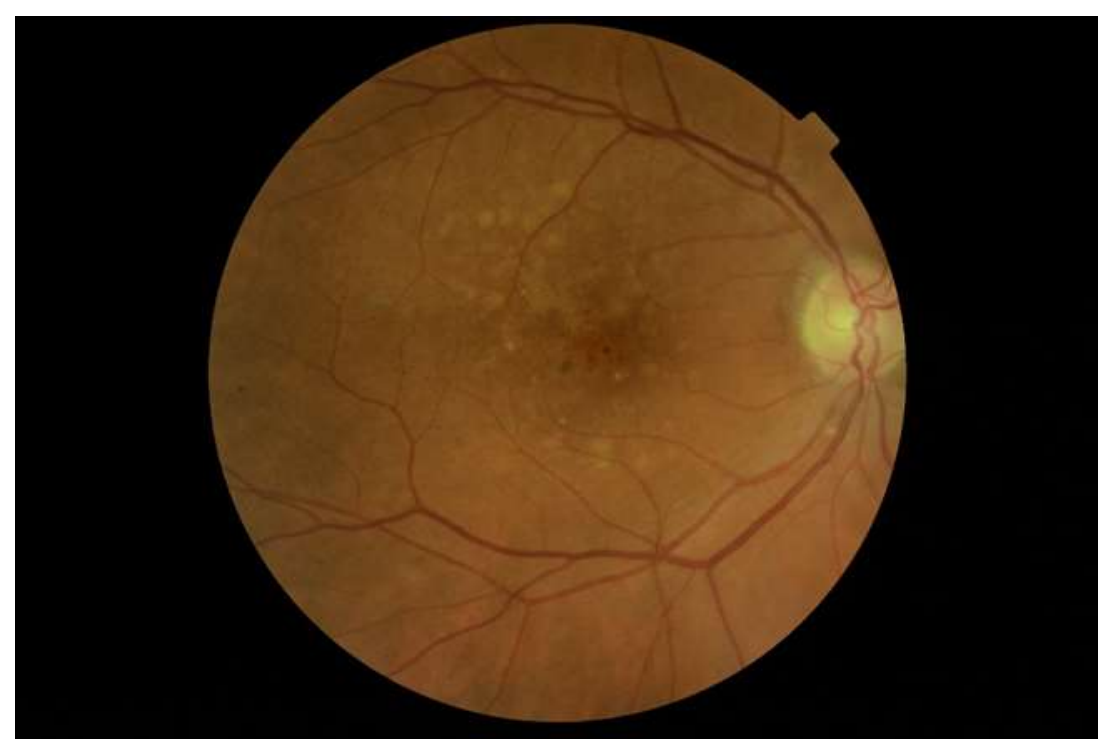

Figure 1. The right eye of a patient with essential thrombocytosis and age-related macular degeneration. Photograph by C.L.

Yang and colleagues did a similar study where all $374 \mathrm{PV}$ patients with the JAK2 mutation attending their medical centre between 2004 and 2012 were examined. Of those, 53 presented with visual disturbances (including cataract, glaucoma, retinal vascular occlusions, dysfunctional tear syndrome, optic neuropathy and transient ocular blindness). Twenty-one patients who experienced transient blindness episodes underwent fluorescein angiography (FA) before and after treatment. The treatment consisted of phlebotomy to a haematocrit below 50\% and Hydroxycarbamide at a dose of $0.5-1.0 \mathrm{~g}$ daily. The arm-choroidal filling time (ACT) and the artery-venous transit time (AVT) was significantly prolonged in PV patients compared to controls. After treatment, the ocular symptoms disappeared in almost all patients and corresponded with recovered choroidal and retinal blood flow. The patients with persisting symptoms still had elevated platelet counts. Furthermore, the authors of the study found a significant positive correlation between ACT and both haematocrit and platelets, and a significant correlation between AVT and haematocrit, and between AVT and haemoglobin [6]. The results above from the study by Dapling et al. [51] should, therefore, be looked upon with caution because they looked at well-treated/asymptomatic patients and Yang et al observed normalized choroidal and retinal blood flow after treatment. 
Willerslev et al. also looked at blood flow in MPN patients. With non-invasive retinal imaging, they demonstrated after successful treatment of the patients increased retinal venous blood velocity, increased retinal arterial blood oxygenation and normalisation of intravascular reflectivity patterns. The study only included seven patients, and further studies are needed to assess the prognostic value of the non-invasive methods they used [39].

Ayintap et al. investigated peripapillary retinal nerve fibre layer thickness (RNFL) in 30 ET patients and compared the thickness with age, sex, race and refractive error-matched controls. ET patient had an average RNFL, which was $8.44 \%$ thinner compared to the controls, but the difference was not statistically significant $(P=0.226)$ [52].

Pekel and colleagues investigated subfoveal choroidal thickness (SFCT), retinal vessel calibre, and ocular pulse amplitude between treated PV patients and healthy adults. There were no statistically significant differences between PV patients and controls. They found an association between SFCT and hematocrit level in both PV patients and healthy adults [53]. In a later study, the same research group investigated ET patients, and again choroidal thickness and pulsatile blood flow were not significantly affected in ET patients. They found a statistically significant difference in retinal arteriolar and venular calibres, which are thinner in ET when compared to age and sex-matched healthy controls [54]. To summarize, the only difference between patients with ET and controls in terms of retinal and choroidal structures is the arteriolar and venular calibres.

Another study found a sustained but reversible neuronal hypofunction of the retina by investigating the dark adaptation in $10 \mathrm{PV}$ patients and compared them to 31 healthy controls. They found impaired dark adaptation in the PV patients and the adaptation markedly improved after treatment [55].

Occlusions of the central vessels causing damage to the retina will be addressed in Section 3.4.

\subsubsection{Optic Nerve}

We found six cases of anterior ischemic optic neuropathy (AION) causing loss of vision due to damage of the optic nerve as a result of ischemia in ET and PV patients, one of them as impending AION and fortunately with full recovery of vision [6,42,56-61].

Extramedullary haematopoiesis is described in a case involving the optic nerve sheath [62].

Papilledema is seen after conditions raising the intracranial pressure, for example, after sagittal sinus thrombosis or jugular vein thrombosis described under vaso-occlusions.

\subsection{Vaso-Occlusions, Haemorrhages and Microangiopathy}

Vaso-occlusion is one of the more severe ocular manifestations, where occlusion of central retinal vessels and the cilioretinal artery in most cases cause retinal ischemia and vision loss. Retinal vascular occlusions in MPNs are the result of acquired defects in the blood components and hyperviscosity, as mentioned earlier, causing microvascular disturbances and disruption of the coagulation cascade. Hyperviscosity occurs from either elevation of the cellular or acellular (protein) elements of the blood [6,36,49,63-65]. The ophthalmologist must be aware of suspicious ocular thrombotic events, where the patient lacks the typical predispositions for vascular occlusions, such as increasing age, hypertension, diabetes mellitus, smoking and glaucoma. The majority of the MPN patients have the JAK2V617F mutation [1]. The JAK2 mutation in itself induces increased erythrocyte adhesion to the endothelium [66] and the elevated red blood cell count, hematocrit and haemoglobin indicative of PV increase blood hyperviscosity. The same is true for the elevated platelet count in ET patients $[40,63,67]$. As mentioned earlier, an association between hyperviscosity and vascular disease of the choroid and retina was found by Yang et al. [6].

Both central retinal artery occlusions (CRAO) [35,57,68-71] and central retinal venous occlusions (CRVO) $[34,37,41,72,73]$ have been reported numerous times in all the three types of MPNs. Other types of retinal occlusions or lateral posterior ciliary artery occlusions have been described [6,14,37,38,72-77]. Interestingly a retrospective audit was conducted on JAK2V617F requests to address the clinical value of requesting this mutation status in patients with retinal vein or artery occlusion. Of 17,332 diagnostic 
requests, 29 included clinical information of either retinal vein/artery occlusion or thrombosis. The haematological abnormalities in these cases were either thrombocytosis, erythrocytosis, elevated haemoglobin and/or haematocrit, or not provided in 10 cases. The JAK2V617F mutation was detected in five patients $(17.2 \%)$ with either raised haemoglobin and/or haematocrit $(n=3)$ or thrombocytosis $(n=2)$ justifying the screening of requesting JAK2V617F mutation status in patients with retinal vein/artery occlusion and an abnormal hemogram [78].

Occlusions in the brain can also cause visual symptoms, and several cases are described. One case of jugular vein thrombosis and following bilateral optic disc oedema with visual loss in a patient with PMF is reported [79] and sagittal sinus thrombosis, some with resulting papilledema are reported in at least six cases associated with PV, and in these cases the ocular manifestation was seen as an initial symptom, [64,80,81].

These cases and studies correlate well with the known fact that these patients have a susceptibility to thromboembolic events.

Haemorrhages in the retina are also seen, and as mentioned in the discussion of the retinal symptoms, the appearance of the fundus in untreated MPNs is often a fundus with venous dilation and tortuosity and haemorrhages $[17,18,37,38,51,56,82,83]$. Cotton wool spots are occasionally also described in the literature $[35,40,41]$ and Roth spots associated with severe anaemia $[20,82]$.

Other cases involving the vasculature of the retina are chronic vasculitis presenting as temporal arthritis/giant cell arthritis in ET patients [84,85].

A single case of Acute zonal occult outer retinopathy (AZOOR) associated with PV and increased levels of factor VIII has been documented. AZOOR is a syndrome of unknown origin and characterised by rapid loss of outer retinal function in one or more large zones. Because of the increased factor VIII, the authors speculate a thrombotic aetiology of the case of AZOOR [86].

\subsection{Neuro-Ophthalmologic Symptoms}

The microvascular circulation disturbances described earlier give rise to neuro-ophthalmological symptoms. Major cerebrovascular events related to MPN disease, including non-fatal strokes and haemorrhages, can cause ocular symptoms $[87,88]$. However, minor thrombotic complications such as transient ocular symptoms are the most frequently observed neuro-ophthalmologic symptoms in MPNs. These symptoms are often described as a part of typical or atypical transient ischemic attacks (TIA) and migraine-like ischemic attacks (MIA) and include blurred vision, transient monocular blindness, amaurosis fugax, hemianopsia, scintillating scotomas and hallucinations. Extraocular symptoms of these attacks can be headaches, nausea, vomiting, syncope, seizures and erythromelalgia, which is attacks of burning pain, erythema and warmth of the toes and occasionally the fingers. Numerous studies have reported on this subject, and some of them include visual symptoms. This section is not an exhaustive list of studies and cases reported on the subject, but relevant examples are discussed. We found several case reports, case series and studies $[4-8,10-13,40,65,89-93]$ reporting on visual symptoms related to TIAs or just reported as "visual disturbances".

Yang and colleagues retrospectively examined $374 \mathrm{PV}$ patients with the JAK2V617F mutation and $13.6 \%$ had visual disturbances as an initial symptom and $41.2 \%$ of these cases were presenting as transient ocular blindness [6]. Interestingly, $67 \%$ of the patients with transient blindness had previously been misdiagnosed with other ocular disorders.

Fenaux et al. retrospectively studied the symptoms at diagnosis of 147 patients with ET and found that $7.5 \%$ had visual symptoms and $63 \%$ of cases were recorded as visual disturbances and the rest as thrombotic events in the ocular structures [7].

Billot et al. described the neurological symptoms that occurred in a series of 37 consecutive ET patients. Neurological symptoms were found in 11 patients $(29.7 \%)$. Three of the patients had symptoms diagnosed as TIAs and one of those presented with amaurosis fugax. Two other patients had symptoms documented as bilateral visual disturbances. In total, three patients $(8.1 \%)$ presented with neuro-ophthalmologic symptoms. The authors compared the characteristics of the patients with 
symptoms to those without and found no difference between the two groups in regard to age, sex, haemoglobin, platelet and leukocyte counts at the time of diagnosis.

Regev et al. recorded symptoms related to ET in 56 patients and followed them for a median of 45 months. Most of the patients received antiplatelet agents (aspirin or/and dipyramidole) and antineoplastic agents (hydroxyurea or busulfan). Visual disturbances were seen in $10.7 \%$ and TIA/cerebrovascular accident in 8.9\% (no information on related visual symptoms) [8]. The authors of this study found no association between platelet counts and types of symptoms and demonstrated that severe complications are not uncommon in patients with ET despite relatively low platelet counts.

A lot of studies report on TIA with no information on visual symptoms. The European Collaboration on Low-Dose Aspirin in Polycythemia Vera (ECLAP) project included 1638 patients with $\mathrm{PV}$. They were not newly diagnosed patients and were receiving treatment (phlebotomy, antineoplastic agents or both). At baseline, 19\% of the patients had a history of cerebral TIA or stroke. Of the total patients, 1120 were enrolled in a prospective observational study to report on the incidence and risk factors for thrombosis [94]. The study does not report on visual symptoms either at baseline or during the prospective study, illustrating the lack of attention given to ocular symptoms. The other 518 patients from the ECLAP were enrolled in a double-blind, placebo-controlled randomized trial to assess the safety and efficacy of low-dose aspirin treatment in patients with PV [95]. The conclusions were that low-dose aspirin could safely prevent thrombotic complications in patients with PV, including minor thrombotic complications such as TIA. In this randomized trial, it was noted that visual symptoms were a part of TIA, but no estimate of the prevalence of ocular symptoms was given. Numerous other studies have investigated the effects of aspirin on symptoms related to MPNs. Michiels and colleagues' research is an example of such studies, and they demonstrated that low-dose aspirin reverses the ocular ischemic disturbances and the other complications related to TIAs and MIAs $[4,10,11,13,89,96]$.

\subsection{Ocular Adverse Effects to Treatment}

Fraundfelder and Fraundfelder reviewed the literature to find out if interferon alfa therapy was associated with anterior ischemic optic neuropathy (AION). They found 36 case reports of AION described in association with interferon alfa therapy and in $67 \%$ of the cases the AION was bilateral. The median duration from treatment start to the onset of AION was 4.5 months. They conclude that the association between interferon alfa treatment and AION can be classified as "possible" according to the World Health Organisation's causality assessment of suspected adverse drug reactions. The "possible" term of an association is defined as "A clinical event, including laboratory test abnormality, with a reasonable time sequence to the administration of the drug, which could also be explained by concurrent disease, or other drugs or chemicals. Information on drug withdrawal may be lacking or unclear". Fraundfelder also reports on other ocular events such as blurred vision and irritative conjunctivitis because the drug is secreted in the tears. Finally, ischemic events are reported, but in less than $1 \%$ of patients treated and the changes often regress while on the drug or if the treatment is stopped [97]. Another review of Lewczuk et al. suggests a possible association between interferon alpha and retinopathy [98].

Two cases of retinitis in patients treated with Ruxolitinib have been reported. One with cytomegalovirus retinitis due to cytomegalovirus [99] and one with toxoplasmosis due to Toxoplasma gondii [100]. Both are cases of opportunistic infections due to the immunosuppressive effect of Ruxolitinib.

\section{Conclusions}

Ocular manifestations are common in patients with MPN and are primarily due to indirect involvement of the ocular structures. The most frequently observed symptoms are those arising from haematological abnormalities due to the elevated blood cell counts and their increased propensity to adhere to each other because of their hyperactivated state, a hallmark of the MPNs. The result 
is impaired microcirculation consequent to circulating microaggregates of leukocytes and platelets, which typically resolve on treatment with aspirin.

Inadequate perfusion of retinal vessels increases the risk of devastating vaso-occlusion in the eyes causing loss of vision, with the JAK2V617F mutation in itself adding to the thrombogenic condition by increasing erythrocyte adhesiveness to the endothelium. Insufficient cerebral perfusion causes the most commonly described symptoms, especially in untreated MPN patients, including monocular blindness, transient blindness, amaurosis fugax, scotomas, hemianopsia, blurring and hallucinations. Some of the symptoms are described as part of transient ischemic attacks.

Other manifestations, such as AMD and hypofunction of the retinal nerve fibre layer, may also be explained by the insufficient blood flow and resulting ischemia, but the inflammatory state in MPN patients may also play a part.

Ocular manifestations are encountered in any of the MPNs and may precede more serious and potentially life-threatening extraocular complications. Therefore, the health personnel and especially the ophthalmologist should be aware of this entity. The possibility of underlying haematological abnormalities should be considered where an obvious underlying ocular cause or typically predisposing factors are not present. A systemic evaluation and a full haematological workup should be done, so timely recognition of the aetiology of the eye manifestation can be followed by prompt and appropriate treatment. Combined ophthalmological and haematological management has the potential to discover these diseases earlier and prevent morbidity and mortality in MPN patients. Additionally, routine ophthalmological screening of all newly diagnosed MPN patients may be a preventive approach for early diagnosis and timely treatment of the ocular manifestations.

Author Contributions: Conceptualization, C.L., H.C.H., and T.L.S.; methodology, C.L., H.C.H., and T.L.S; formal analysis, C.L.; investigation, C.L.; writing-original draft preparation, C.L.; writing-review and editing, C.L., H.C.H., and T.L.S.; supervision, H.C.H. and T.L.S.; funding acquisition, C.L. and T.L.S. All authors have read and agreed to the published version of the manuscript.

Acknowledgments: This research was funded by Fight for Sight, Denmark, and Region Zealand's fund for research promotion.

Conflicts of Interest: The authors declare no conflicts of interest. The funding sponsors had no role in the design of the study; in the collection, analyses, or interpretation of data; in the writing of the manuscript, and in the decision to publish the results.

\section{References}

1. Rampal, R.; Al-Shahrour, F.; Abdel-Wahab, O.; Patel, J.P.; Brunel, J.-P.; Mermel, C.H.; Bass, A.J.; Pretz, J.; Ahn, J.; Hricik, T.; et al. Integrated Genomic Analysis Illustrates the Central Role of JAK-STAT Pathway Activation in Myeloproliferative Neoplasm Pathogenesis. Blood 2014, 123, e123-e133. [CrossRef] [PubMed]

2. Tefferi, A.; Pardanani, A. Myeloproliferative Neoplasms. JAMA Oncol. 2015, 1, 97. [CrossRef] [PubMed]

3. Spivak, J.; Spivak, J.L. Myeloproliferative Neoplasms. N. Engl. J. Med. 2017, 376. [CrossRef] [PubMed]

4. Michiels, J.J.; Koudstaal, P.J.; Mulder, A.H.; van Vliet, H.H. Transient Neurologic and Ocular Manifestations in Primary Thrombocythemia. Neurology 1993, 43, 1107-1110. [CrossRef] [PubMed]

5. Jabaily, J.; Iland, H.J.; Laszlo, J.; Massey, E.W.; Faguet, G.B.; Brière, J.; Landaw, S.A.; Pisciotta, A.V. Neurologic Manifestations of Essential Thrombocythemia. Ann. Intern. Med. 1983, 99, 513-518. [CrossRef] [PubMed]

6. Yang, H.S.; Joe, S.G.; Kim, J.-G.; Park, S.H.; Ko, H.S. Delayed Choroidal and Retinal Blood Flow in Polycythaemia Vera Patients with Transient Ocular Blindness: A Preliminary Study with Fluorescein Angiography. Br. J. Haematol. 2013, 161, 745-747. [CrossRef]

7. Fenaux, P.; Simon, M.; Caulier, M.T.; Lai, J.L.; Goudemand, J.; Bauters, F. Clinical Course of Essential Thrombocythemia in 147 Cases. Cancer 1990, 66, 549-556. [CrossRef]

8. Regev, A.; Stark, P.; Blickstein, D.; Lahav, M. Thrombotic Complications in Essential Thrombocythemia with Relatively Low Platelet Counts. Am. J. Hematol. 1997, 56, 168-172. [CrossRef]

9. Billot, S.; Kouroupi, E.G.; Le Guilloux, J.; Cassinat, B.; Jardin, C.; Laperche, T.; Fenaux, P.; Carpentier, A.F.; Kiladjian, J.-J. Neurological Disorders in Essential Thrombocythemia. Haematologica 2011, 96, 1866-1869. [CrossRef] 
10. Michiels, J.J.; van Genderen, P.J.; Jansen, P.H.; Koudstaal, P.J. Atypical Transient Ischemic Attacks in Thrombocythemia of Various Myeloproliferative Disorders. Leuk. Lymphoma 1996, 22, 65-70. [CrossRef]

11. Michiels, J.J.; Berneman, Z.; Gadisseur, A.; Lam, K.H.; De Raeve, H.; Schroyens, W. Aspirin-Responsive, Migraine-like Transient Cerebral and Ocular Ischemic Attacks and Erythromelalgia in JAK2-Positive Essential Thrombocythemia and Polycythemia Vera. Acta. Haematol. 2015, 133, 56-63. [CrossRef] [PubMed]

12. Koudstaal, P.J.; Koudstaal, A. Neurologic and Visual Symptoms in Essential Thrombocythemia: Efficacy of Low, Dose Aspirin. Semin. Thromb. Hemost. 1997, 23, 365-370. [CrossRef] [PubMed]

13. Michiels, J.J.; Berneman, Z.N.; Schroyens, W.; Van Vliet, H.H.D.M. Pathophysiology and Treatment of Platelet-Mediated Microvascular Disturbances, Major Thrombosis and Bleeding Complications in Essential Thrombocythaemia and Polycythaemia Vera. Platelets 2004, 15, 67-84. [CrossRef] [PubMed]

14. Liu, M.; Lee, A.G.; Rice, L.; Lambert, H.M. Bilateral Retinal Vascular Occlusive Disease in Essential Thrombocythemia. Retina 1999, 19, 563-564. [CrossRef] [PubMed]

15. Jensen, M.K.; de Nully Brown, P.; Lund, B.V.; Nielsen, O.J.; Hasselbalch, H.C. Increased Platelet Activation and Abnormal Membrane Glycoprotein Content and Redistribution in Myeloproliferative Disorders. $\mathrm{Br}$. J. Haematol. 2000, 110, 116-124. [CrossRef]

16. de Lacerda, J.F.; Oliveira, S.N. Chronic Myeloproliferative Diseases. Handb. Clin. Neurol. 2014, 120, $1073-1081$. [CrossRef]

17. Carraro, M.C.; Rossetti, L.; Gerli, G.C. Prevalence of Retinopathy in Patients with Anemia or Thrombocytopenia. Eur. J. Haematol. 2001, 67, 238-244. [CrossRef]

18. Haskes, C.; Gagnon, K. Retinal Manifestations of Idiopathic Myelofibrosis, a Hematologic Disorder. J. Am. Optom. Assoc. 1998, 69, 319-328.

19. Charles, K.S.; Leelah, N.; Boodoo, L.; Murray, D.C. Ophthalmic Manifestations of Haematological Disorders. West Indian Med. J. 2013, 62, 99-103.

20. Lin, A.L.; Burnham, J.M.; Pang, V.; Idowu, O.; Iyer, S. OCULAR MANIFESTATIONS OF PRIMARY MYELOFIBROSIS. Retin. Cases Brief Rep. 2016, 10, 364-367. [CrossRef]

21. Ghazi, N.G.; Bowman, A.M.; Shields, M.D. Bilateral Lacrimal System Involvement by Sclerosing Extramedullary Hematopoietic Tumor. Ophthalmic Plast. Reconstr. Surg. 2006, 22, 296-298. [CrossRef] [PubMed]

22. Sharma, T.; Grewal, J.; Gupta, S.; Murray, P.I. Ophthalmic Manifestations of Acute Leukaemias: The Ophthalmologist's Role. Eye 2004, 18, 663-672. [CrossRef] [PubMed]

23. Yuen, H.K.L.; Mahesh, L.; Tse, R.K.K.; Yau, K.C.; Chan, N.; Lam, D.S.C. Orbital Sclerosing Extramedullary Hematopoietic Tumor. Arch. Ophthalmol. 2005, 123, 689-691. [CrossRef]

24. Sohawon, D.; Lau, K.K.; Lau, T.; Bowden, D.K. Extra-Medullary Haematopoiesis: A Pictorial Review of Its Typical and Atypical Locations. J. Med. Imaging Radiat. Oncol. 2012, 56, 538-544. [CrossRef]

25. YAMAMOTO, K.; MIWA, Y.; ABE-SUZUKI, S.; ABE, S.; KIRIMURA, S.; ONISHI, I.; KITAGAWA, M.; KURATA, M.; Kirimura, S.; Kirimura, S.; et al. Extramedullary Hematopoiesis: Elucidating the Function of the Hematopoietic Stem Cell Niche (Review). Mol. Med. Rep. 2016, 13, 587-591. [CrossRef] [PubMed]

26. Neufeld, K.R.; Price, K.; Woodward, J.A. Massive Eyelid Thickening in Pachydermoperiostosis with Myelofibrosis. Ophthal. Plast. Reconstr. Surg. 2009, 25, 316-318. [CrossRef]

27. Tanaka, H.; Maehama, S.; Imanaka, F.; Sakai, A.; Abe, K.; Hamada, M.; Yamashita, J.; Klmura, A.; Imamura, N.; Fujimuraand, K.; et al. Pachydermoperiostosis with Myelofibrosis and Anemia: Report of a Case of Anemiaof Multifactorial Causes and Its Improvement with Steroid Pulse and Iron Therapy. Jpn. J. Med. 1991, 30, 73-80. [CrossRef]

28. Na, J.; Choi, S.Y.; Baek, S.; Lee, H. Hemorrhage and Infarction of the Conjunctiva and Orbit in Essential Thrombocythemia. J. Craniofac. Surg. 2017, 28, 750-751. [CrossRef]

29. Tefferi, A.; Fonseca, R.; Pereira, D.L.; Hoagland, H.C. A Long-Term Retrospective Study of Young Women With Essential Thrombocythemia. Mayo Clin. Proc. 2001, 76, 22-28. [CrossRef]

30. Carobbio, A.; Thiele, J.; Passamonti, F.; Rumi, E.; Ruggeri, M.; Rodeghiero, F.; Randi, M.L.; Bertozzi, I.; Vannucchi, A.M.; Antonioli, E.; et al. Risk Factors for Arterial and Venous Thrombosis in WHO-Defined Essential Thrombocythemia: An International Study of 891 Patients. Blood 2011, 117, 5857-5859. [CrossRef] 
31. Lindsey, J.; Insler, M.S. Polycythemia Rubra Vera and Conjunctival Vascular Congestion. Ann. Ophthalmol. 1985, 17, 62-63. [PubMed]

32. Cuttler, N.; Heidemann, D.; Cendrowski, C.; Armin, A.-R.; Folberg, R. Extramedullary Hematopoiesis of the Conjunctiva Presenting as Active Systemic Disease in a Patient with Myelofibrosis. Cornea 2014, 33, 1352-1354. [CrossRef] [PubMed]

33. Sorensen, T.L.; Mortzos, P. Iritis, Ptosis, and Sequential Severe Loss of Vision in a Patient with Essential Thrombocytosis. Eye 2010. [CrossRef] [PubMed]

34. Yoshizumi, M.O.; Townsend-Pico, W. Essential Thrombocythemia and Central Retinal Vein Occlusion with Neovascular Glaucoma. Am. J. Ophthalmol. 1996, 121, 728-730. [CrossRef]

35. Strassman, I.; Silverstone, B.Z.; Seelenfreund, M.H.; Sheer, A.; Berson, D. Essential Thrombocythemia: A Rare Case of Central Retinal Artery Occlusion. Metab. Pediatr. Syst. Ophthalmol. 1991, 14, 18-20.

36. Rajagopal, R.; Apte, R.S. Seeing through Thick and through Thin: Retinal Manifestations of Thrombophilic and Hyperviscosity Syndromes. Surv. Ophthalmol. 2016, 61, 236-247. [CrossRef]

37. Imasawa, M.; Iijima, H. Multiple Retinal Vein Occlusions in Essential Thrombocythemia. Am. J. Ophthalmol. 2002, 133, 152-155. [CrossRef]

38. Singer, G. Migrating Emboli of Retinal Arteries in Thrombocythaemia. Br. J. Ophthalmol. 1969, 53, $279-281$. [CrossRef]

39. Willerslev, A.; Hansen, M.M.; Klefter, O.N.; Bjerrum, O.W.; Hasselbalch, H.C.; Clemmensen, S.N.; Larsen, M.; Munch, I.C. Non-Invasive Imaging of Retinal Blood Flow in Myeloproliferative Neoplasms. Acta Ophthalmol. 2017, 95, 146-152. [CrossRef]

40. Ahn, B.-Y.; Choi, K.-D.; Choi, Y.-J.; Jea, S.-Y.; Lee, J.-E. Isolated Monocular Visual Loss as an Initial Manifestation of Polycythemia Vera. J. Neurol. Sci. 2007, 258, 151-153. [CrossRef]

41. Raval, V.; Sudana, P.; Das, T. Idiopathic Myelofibrosis Causing Inflammatory Central Retinal Vein Occlusion Mimicking Frosted Branch Angiitis. BMJ Case Rep. 2019, 12. [CrossRef] [PubMed]

42. Rue, K.S.; Hirsch, L.K.; Sadun, A.A. Impending Anterior Ischemic Optic Neuropathy with Elements of Retinal Vein Occlusion in a Patient on Interferon for Polycythemia Vera. Clin. Ophthalmol. 2012, 1763-1765. [CrossRef] [PubMed]

43. Rodgin, S.G. Retinopathy of Blood Dyscrasias. J. Am. Optom. Assoc. 1993, 64, 769-779. [PubMed]

44. Wong, W.L.; Su, X.; Li, X.; Cheung, C.M.G.; Klein, R.; Cheng, C.-Y.; Wong, T.Y. Global Prevalence of Age-Related Macular Degeneration and Disease Burden Projection for 2020 and 2040: A Systematic Review and Meta-Analysis. Lancet. Glob. Heal. 2014, 2, e106-e116. [CrossRef]

45. Grunwald, J.E.; Metelitsina, T.I.; DuPont, J.C.; Ying, G.-S.; Maguire, M.G. Reduced Foveolar Choroidal Blood Flow in Eyes with Increasing AMD Severity. Investig. Opthalmology Vis. Sci. 2005, 46, 1033. [CrossRef] [PubMed]

46. Coleman, D.J.; Silverman, R.H.; Rondeau, M.J.; Lloyd, H.O.; Khanifar, A.A.; Chan, R.V.P. Age-Related Macular Degeneration: Choroidal Ischaemia? Br. J. Ophthalmol. 2013, 97, 1020-1023. [CrossRef]

47. Friedman, E.; Krupsky, S.; Lane, A.M.; Oak, S.S.; Friedman, E.S.; Egan, K.; Gragoudas, E.S. Ocular Blood Flow Velocity in Age-Related Macular Degeneration. Ophthalmology 1995, 102, 640-646. [CrossRef]

48. Chen, J.C.; Fitzke, F.W.; Pauleikhoff, D.; Bird, A.C. Functional Loss in Age-Related Bruch's Membrane Change with Choroidal Perfusion Defect. Invest. Ophthalmol. Vis. Sci. 1992, 33, 334-340.

49. Krishnan, R. Peripheral Retinal Neovascularization Associated with Polycythemia Rubra Vera. Jpn. J. Ophthalmol. 2009, 53, 188-189. [CrossRef]

50. Kim, M.J.; Yu, H.G. Case of Bilateral Retinal Neovascularization Associated with Chronic Idiopathic Myelofibrosis. Korean J. Ophthalmol. 2010, 24, 131-133. [CrossRef]

51. Dapling, R.B.; Snowden, J.A.; West, J.; Talbot, J.F.; Nelson, M.E.; Greaves, M. The Microvasculature in Myeloproliferative Disease. A Study Using Retinal Fluorescein Angiography. Clin. Lab. Haematol. 1996, 18, 277-279. [PubMed]

52. Ayintap, E.; Cetin, G.; Sadigov, F.; Artunay, O.; Akkan, J.C.U.; Koytak, I.A.; Tuncer, K. Peripapillary Retinal Nerve Fiber Layer Changes in Asymptomatic Essential Thrombocythemia Patients. Curr. Eye Res. 2014, 39, 1216-1220. [CrossRef] [PubMed] 
53. Pekel, G.; Dogu, M.H.; Keskin, A.; Acer, S.; Yagci, R.; Kasikci, A.; Cetin, E.N. Subfoveal Choroidal Thickness Is Associated with Blood Hematocrit Level. Ophthalmologica. 2015, 234, 55-59. [CrossRef] [PubMed]

54. Pekel, G.; Dogu, M.H.; Sari, H.I.; Acer, S.; Kasikci, A.; Yagci, R.; Cetin, E.N. Retinal Vessel Caliber, Choroidal Thickness and Ocular Pulse Amplitude Measurements in Essential Thrombocythemia. Middle East Afr. J. Ophthalmol. 2016, 23, 84-88. [CrossRef] [PubMed]

55. Havelius, U.; Berglund, S.; Falke, P.; Hindfelt, B.; Krakau, T. Impaired Dark Adaptation in Polycythemia. Improvement after Treatment. Acta. Ophthalmol. Scand. 2000, 78, 53-57. [CrossRef] [PubMed]

56. Tonz, M.S.; Rigamonti, V.; Iliev, M.E. Simultaneous, Bilateral Anterior Ischemic Optic Neuropathy (AION) in Polycythemia Vera: A Case Report. Klin. Monbl. Augenheilkd. 2008, 225, 504-506. [CrossRef]

57. Ganesan, S.; Raman, R.; Sharma, T. Polycythemia Causing Posterior Segment Vascular Occlusions. Oman J Ophthalmol. 2017, 10, 33-35. [CrossRef]

58. Rothstein, T. Bilateral, Central Retinal Vein Closure as the Initial Manifestation of Polycythemia. Am. J. Ophthalmol. 1972, 74, 256-260. [CrossRef]

59. Klein, J.P.; Cohen, A.B.; Kimberly, W.T.; Shah, A.S.; Leiderman, Y.I.; Cestari, D.M.; Dinkin, M.J. Diffusion-Weighted Magnetic Resonance Imaging of Bilateral Simultaneous Optic Nerve Infarctions. Arch. Neurol. 2009, 66, 132-133. [CrossRef]

60. Gerding, H. Bilateral Non-Arteritic Anterior Ischaemic Optic Neuropathy (NAION) Associated with Essential Thrombocytosis. Klin. Monbl. Augenheilkd. 2013, 230, 430-431. [CrossRef]

61. Vardizer, Y.; Linhart, Y.; Loewenstein, A.; Garzozi, H.; Mazawi, N.; Kesler, A. Interferon-Alpha-Associated Bilateral Simultaneous Ischemic Optic Neuropathy. J. Neuroophthalmol. 2003, 23, 256-259. [CrossRef] [PubMed]

62. Ohtsubo, M.; Hayashi, K.; Fukushima, T.; Chiyoda, S.; Takahara, O. Case Report: Intracranial Extramedullary Haematopoiesis in Postpolycythemic Myelofibrosis. Br. J. Radiol. 1994, 67, 299-302. [CrossRef] [PubMed]

63. Adams, B.D.; Baker, R.; Lopez, J.A.; Spencer, S. Myeloproliferative Disorders and the Hyperviscosity Syndrome. Emerg. Med. Clin. North Am. 2009, 27, 459-476. [CrossRef] [PubMed]

64. Melamed, E.; Rachmilewitz, E.A.; Reches, A.; Lavy, S. Aseptic Cavernous Sinus Thrombosis after Internal Carotid Arterial Occlusion in Polycythaemia Vera. J. Neurol. Neurosurg. Psychiatry 1976, 39, 320-324. [CrossRef]

65. Kwaan, H.; Kwaan, H.C. Hyperviscosity in Polycythemia Vera and Other Red Cell Abnormalities. Semin. Thromb. Hemost. 2003, 29. [CrossRef]

66. Wautier, M.-P.; El Nemer, W.; Gane, P.; Rain, J.-D.; Cartron, J.-P.; Colin, Y.; Le Van Kim, C.; Wautier, J.-L. Increased Adhesion to Endothelial Cells of Erythrocytes from Patients with Polycythemia Vera Is Mediated by Laminin Alpha5 Chain and Lu/BCAM. Blood 2007, 110, 894-901. [CrossRef]

67. Thomas, D.J.; Marshall, J.; Russell, R.W.; Wetherley-Mein, G.; du Boulay, G.H.; Pearson, T.C.; Symon, L.; Zilkha, E. Effect of Haematocrit on Cerebral Blood-Flow in Man. Lancet. 1977, 2, 941-943. [CrossRef]

68. Rao, K.; Shenoy, S.B.; Kamath, Y.; Kapoor, S. Central Retinal Artery Occlusion as a Presenting Manifestation of Polycythaemia Vera. BMJ Case Rep. 2016. [CrossRef]

69. Barabas, A.P.; Offen, D.N.; Meinhard, E.A. The Arterial Complications of Polycythaemia Vera. Br. J. Surg. 1973, 60, 183-187. [CrossRef]

70. Dhrami-Gavazi, E.; Lee, W.; Horowitz, J.D.; Odel, J.; Mukkamala, S.K.; Blumberg, D.M.; Weiss, M.; Winn, B.J. Jak2 Mutation-Positive Polycythemia Vera Presenting as Central Retinal Artery Occlusion. Retin. Cases Brief Rep. 2015, 9, 127-130. [CrossRef]

71. Arikan, G.; Saatci, A.O.; Kahraman, S.; Piskin, O.; Men, S.; Undar, B. Central Retinal Artery Occlusion as the Presenting Sign of Essential Thrombocythemia. Turkish J. Hematol. 2011, 28, 146-148. [CrossRef] [PubMed]

72. BIRGE, H.L. New Theories of Vascular Disease; with Special Reference to the Syndrome of Polycythemia in Ocular Pathology. Am. J. Ophthalmol. 1955, 39, 362-369. [CrossRef]

73. Tache, J.E.; Saffra, N.; Marshak, H.; Aithal, S.; Novetsky, A.; Huang, Y.-W. Retinal Vein Thrombosis as the Presenting Symptom of Essential Thrombocythemia. Am. J. Med. Sci. 2005, 329, 139-140. [CrossRef] [PubMed]

74. Garrido-Hermosilla, A.M.; Mendez-Muros, M.; Diaz-Granda, M.J. Retinal Venovenous Anastomoses on Swept-Source Optical Coherence Tomography Angiography in a Patient with Polycythemia. J. Fr. Ophtalmol. 2019, 42, 327-328. [CrossRef] [PubMed] 
75. Elasri, F.; Souhail, H.; Reda, K.; Iferkhass, S.; Idrissi, A.; Naoumi, A.; Oubaaz, A. Isolated Cilioretinal Artery Occlusion as an Initial Manifestation of Polycythemia Vera. Middle East Afr. J. Ophthalmol. 2010, 17, $275-277$. [CrossRef] [PubMed]

76. Nobacht, S.; Cruysberg, J.R.M.; Deutman, A.F. Peripheral Retinal Nonperfusion Associated with Essential Thrombocytosis. Am. J. Ophthalmol. 1999, 127, 101-102. [CrossRef]

77. Rospond-Kubiak, I.; Oszkinis, G.; Kociecki, J. Retinal Intra-Arterial Thrombocytic Material Revealing Essential Thrombocythemia. JAMA Ophthalmol. 2016, 134. [CrossRef]

78. Langabeer, S.E. The JAK2 V617F Mutation in Retinal Vein or Artery Occlusion. EXCLI J. 2019, 18, 127-128.

79. Mateo, J.; Ascaso, F.J.; Jiménez, B.; Cristóbal, J.A. Jugular Venous Thrombosis Secondary to Idiopathic Myelofibrosis: A Rare Cause of Bilateral Optic Disc Swelling. Clin. Exp. Optom. 2015, 98, 286-289. [CrossRef]

80. Parija, S.; Mohapatra, M.M.; Pattnaik, B.K. Polycythemia Vera Presenting with Bilateral Papilledema: A Rare Case Report. Indian J. Ophthalmol. 2008, 56, 327-329. [CrossRef]

81. Nithyanandam, S. Polycythemia Vera Presenting with Bilateral Papilledema. Indian J. Ophthalmol. $2009,325$. [CrossRef] [PubMed]

82. Blood, A.M.; Lowenthal, E.A.; Nowakowski, R.W. Retinopathy Secondary to Anemia from Myeloid Metaplasia in Polycythemia Vera. J. Am. Optom. Assoc. 1997, 68, 734-738.

83. Nagy, G.; Gat, G.; Racz, M.; Mailath, L. The Optic Fundus in Polycythaemia Vera. Acta. Med. Acad. Sci. Hung. 1969, 26, 351-355. [PubMed]

84. Montalto, M.; Biolato, M.; Gallo, A.; Racco, S.; Marrone, G.; Manna, R.; Grieco, A.; Gasbarrini, G. Severe Giant Cell Arteritis Associated with Essential Thrombocythaemia. Int. J. Immunopathol. Pharmacol. 2010, 1271-1274. [CrossRef] [PubMed]

85. Espinosa, G.; Font, J.; Muñoz-Rodríguez, F.J.; Cervera, R.; Ingelmo, M. Myelodysplastic and Myeloproliferative Syndromes Associated with Giant Cell Arteritis and Polymyalgia Rheumatica: A Coincidental Coexistence or a Causal Relationship? Clin. Rheumatol. 2002, 21, 309-313. [CrossRef]

86. Mahendradas, P.; Shetty, R.; Avadhani, K.; Ross, C.; Gupta, A.; Shetty, B.K. Polycythemia Vera and Increased Hemophilic Factor VIII Causing Acute Zonal Occult Outer Retinopathy: A Case Report. Ocul. Immunol. Inflamm. 2010, 18, 319-321. [CrossRef]

87. Hoyt, C.S. Acquired “Double Elevator" Palsy and Polycythemia Vera. J. Pediatr. Ophthalmol. Strabismus 1978, 15, 362-365.

88. Prabhakaran, V.C.; Chohan, A.; Husain, R.; Andrew, N.C. Third Nerve Paralysis as a Presenting Sign of Essential Thrombocythaemia. Eye 2006, 1483-1484. [CrossRef]

89. Michiels, J.J.; Berneman, Z.; Schroyens, W.; Koudstaal, P.J.; Lindemans, J.; Neumann, H.A.M.; van Vliet, H.H.D.M. Platelet-Mediated Erythromelalgic, Cerebral, Ocular and Coronary Microvascular Ischemic and Thrombotic Manifestations in Patients with Essential Thrombocythemia and Polycythemia Vera: A Distinct Aspirin-Responsive and Coumadin-Resistant Arterial Thromboph. Platelets 2006, 17, 528-544. [CrossRef]

90. Kuriyama, M.; Ishii, N.; Umezaki, H.; Kano, M. Polycythemia Vera and Transient Monocular Blindness. Observation of the Platelet Embolic Phenomena in the Ocular Fundus. Eur. Neurol. 1977, 16. [CrossRef]

91. Austin, J.H. Amaurosis Fugax and Thrombocythemia. Neurology 1987, 1887. [CrossRef] [PubMed]

92. Berdel, W.E.; Theiss, W.; Fink, U.; Rastetter, J. Peripheral Arterial Occlusion and Amaurosis Fugax as the First Manifestation of Polycythemia Vera- A Case Report. Blut 1984, 48, 177-180. [CrossRef] [PubMed]

93. Kremer, M.; Lambert, C.D.; Lawton, N. Progressive Neurological Deficits in Primary Polycythaemia. Br. Med. J. 1972, 3, 216-218. [CrossRef] [PubMed]

94. Finazzi, G.; low-dose aspirin in polycythemia (ECLAP). A Prospective Analysis of Thrombotic Events in the European Collaboration Study on Low-Dose Aspirin in Polycythemia (ECLAP). Pathol. Biol. 2004, 52, 285-288. [CrossRef] [PubMed]

95. Landolfi, R.; Marchioli, R.; Kutti, J.; Gisslinger, H.; Tognoni, G.; Patrono, C.; Barbui, T. Efficacy and Safety of Low-Dose Aspirin in Polycythemia Vera. N. Engl. J. Med. 2004, 350, 114-124. [CrossRef] [PubMed]

96. Santisakultarm, T.P.; Paduano, C.Q.; Stokol, T.; Southard, T.L.; Nishimura, N.; Skoda, R.C.; Olbricht, W.L.; Schafer, A.I.; Silver, R.T.; Schaffer, C.B. Stalled Cerebral Capillary Blood Flow in Mouse Models of Essential Thrombocythemia and Polycythemia Vera Revealed by in Vivo Two-Photon Imaging. J. Thromb. Haemost. 2014, 12, 2120-2130. [CrossRef] 
97. Fraunfelder, F.W.; Fraunfelder, F.T. Interferon Alfa-Associated Anterior Ischemic Optic Neuropathy. Ophthalmology 2011, 118, 408-411. [CrossRef]

98. Lewczuk, N.; Zdebik, A.; Boguslawska, J. Interferon Alpha 2a and 2b in Ophthalmology: A Review. J. Interferon Cytokine Res. 2019, 39, 259-272. [CrossRef]

99. von Hofsten, J.; Johnsson Forsberg, M.; Zetterberg, M. Cytomegalovirus Retinitis in a Patient Who Received Ruxolitinib. N. Engl. J. Med. 2016, 374, 296-297. [CrossRef]

100. Goldberg, R.A.; Reichel, E.; Oshry, L.J. Bilateral Toxoplasmosis Retinitis Associated with Ruxolitinib. N. Engl. J. Med. 2013, 369, 681-683. [CrossRef]

C 2020 by the authors. Licensee MDPI, Basel, Switzerland. This article is an open access article distributed under the terms and conditions of the Creative Commons Attribution (CC BY) license (http://creativecommons.org/licenses/by/4.0/). 